\title{
Cardiac Arrest during Competitive Sports
}

TO THE EDITOR: The suggestion by Landry et al. that the value of preparticipation screening is in question is premature. The conclusions of their study are limited by its retrospective nature and the multiple assumptions made, particularly relating to the diagnosis of causative conditions.

The study results are not generalizable to the wider population of competitive athletes. The overall incidence of sudden cardiac arrest of 0.76 cases per 100,000 athlete-years was driven large- 


\begin{tabular}{|c|c|c|c|c|c|}
\hline \multirow[t]{2}{*}{ Sport } & $\begin{array}{c}\text { Sudden Cardiac } \\
\text { Arrests per 100,000 } \\
\text { Athlete-yr }\end{array}$ & $\begin{array}{l}\text { Sudden Cardiac } \\
\text { Arrests, } \\
\text { 2009-2014 }\end{array}$ & $\begin{array}{r}\text { Athletes } \\
\text { in } 2012\end{array}$ & $\begin{array}{c}\text { Athlete-yr of } \\
\text { Observation, } \\
\text { 2009-2014 }\end{array}$ & $\begin{array}{c}\text { Percent of } \\
\text { Total Athlete } \\
\text { Population }\end{array}$ \\
\hline & \multicolumn{2}{|c|}{ number } & \multicolumn{2}{|c|}{ estimated number } & \\
\hline Jujitsu & 27.100 & 2 & 1,230 & 7,380 & 0.3 \\
\hline Soccer & 5.918 & 4 & 11,265 & 67,590 & 3.2 \\
\hline Rugby & 3.771 & 1 & 4,420 & 26,520 & 1.3 \\
\hline Basketball & 3.448 & 2 & 9,668 & 58,008 & 2.7 \\
\hline Baseball & 2.628 & 1 & 6,343 & 38,058 & 1.8 \\
\hline Race events $†$ & 0.908 & 4 & 73,382 & 440,292 & 20.8 \\
\hline Ice hockey & 0.286 & 2 & 116,390 & 698,340 & 33.0 \\
\hline All sportsț & 0.757 & 16 & 352,499 & $2,114,994$ & 100.0 \\
\hline
\end{tabular}

* Adapted from Landry et al.

$\uparrow$ This category includes events such as marathons, biathlons, triathlons, and obstacle course races.

$\checkmark$ This category includes all sports that were included in the study by Landry et al.

ly by the very low incidence of sudden cardiac arrest among ice hockey players, who composed one third of the population of athletes in the study. However, in Ontario, the incidence of sudden cardiac arrest among athletes who participate in other sports such as jujitsu and popular sports such as soccer and basketball is much higher than the incidence among ice hockey players (Table 1).

Finally, the race or ethnic group of the athletes needs to be taken into account, since data from Harmon et al. show the highest incidence of sudden cardiac arrest among black male athletes. ${ }^{1}$ Therefore, more prospective, multinational registries in populations of greater ethnic diversity than the population in the study by Landry et al. are required before any firm conclusions can be reached. ${ }^{2}$

Andrew D'Silva, M.B., B.S.

Michael Papadakis, M.D.

Sanjay Sharma, M.D.

St. George's, University of London

London, United Kingdom

ssharma21@hotmail.com

Drs. D'Silva, Papadakis, and Sharma report receiving research grant support from the charitable organization Cardiac Risk in the Young, which supports cardiovascular screening of young persons. No other potential conflict of interest relevant to this letter was reported.

1. Harmon KG, Asif IM, Maleszewski JJ, et al. Incidence, cause, and comparative frequency of sudden cardiac death in National Collegiate Athletic Association athletes: a decade in review. Circulation 2015;132:10-9.
2. Solberg EE, Borjesson $M$, Sharma $S$, et al. Sudden cardiac arrest in sports - need for uniform registration: a position paper from the Sport Cardiology Section of the European Association for Cardiovascular Prevention and Rehabilitation. Eur J Prev Cardiol 2016;23:657-67.

DOI: $10.1056 /$ NEJMc1802593 